\title{
Potent antitumor activity of Oct4 and hypoxia dual-regulated oncolytic adenovirus against bladder cancer
}

\author{
C-S Lu ${ }^{1,7}$, J-L Hsieh ${ }^{2,7}$, C-Y Lin ${ }^{1}$, H-W Tsai ${ }^{1}$, B-H Su${ }^{1}$, G-S Shieh ${ }^{3}$, Y-C Su${ }^{1}$, C-H Lee ${ }^{4}$, M-Y Chang ${ }^{5}$, C-L Wu ${ }^{1}$ and A-L Shiau ${ }^{6}$
}

\begin{abstract}
Most solid tumors undergo hypoxia, leading to rapid cell division, metastasis and expansion of a cell population with hallmarks of cancer stem cells (CSCs). Tumor-selective replication of oncolytic adenoviruses may be hindered by oxygen deprivation in tumors. It is desirable to develop a potent oncolytic adenovirus, retaining its antitumor activity even in a hypoxic environment. We have previously generated an Oct4-dependent oncolytic adenovirus, namely Ad9OC, driven by nine copies of the Oct4 response element (ORE) for specifically killing Oct4-overexpressing bladder tumors. Here, we developed a novel Oct4 and hypoxia dual-regulated oncolytic adenovirus, designated AdLCY, driven by both hypoxia response element (HRE) and ORE. We showed that hypoxiainducible factor (HIF)-2a and Oct4 were frequently overexpressed in hypoxic bladder cancer cells, and HIF-2a was involved in HRE-dependent and Oct4 transactivation. AdLCY exhibited higher cytolytic activities than Ad9OC against hypoxic bladder cancer cells, while sparing normal cells. AdLCY exerted potent antitumor effects in mice bearing human bladder tumor xenografts and syngeneic bladder tumors. It could target hypoxic CD44- and CD133-positive bladder tumor cells. Therefore, AdLCY may have therapeutic potential for targeting hypoxic bladder tumors and CSCs. As Oct4 is expressed in various cancers, AdLCY may be further explored as a broad-spectrum anticancer agent.
\end{abstract}

Gene Therapy (2015) 22, 305-315; doi:10.1038/gt.2014.122; published online 15 January 2015

\section{INTRODUCTION}

Hypoxia is a common feature of growing solid tumors. Adaptation to low oxygen condition in cells results in the transcriptional activation of more than 100 genes that regulate key aspects of tumorigenesis, including angiogenesis, metabolism, proliferation, invasion and metastasis. ${ }^{1}$ Promoters containing hypoxia response element (HRE) can be transactivated by hypoxia and drive-related gene expressions, leading to defective vasculogenesis and abnormal metabolic activity when tumors progress. Hypoxia-inducible factor (HIF)-1, which is an oxygen-sensitive transcriptional activator, primarily mediates this response. HIF-1 consists of two subunits, namely an oxygen-regulated subunit HIF-1a (or its paralogs HIF-2a and HIF-3a) and a constitutively expressed subunit HIF- $1 \beta .^{2} \mathrm{HIF}-1 \mathrm{a}$ is degraded via the ubiquitin-proteasome pathway in normoxia. Whereas the HIF-1 a subunit becomes stable and regulates the expression of target genes in hypoxia. Furthermore, unusual overexpression of HIF-1a has been found in various cancers. HIF-1a preferentially induces genes encoding glycolytic enzymes, whereas HIF-2a induces genes involved in tumor invasion, such as matrix metalloproteinases and the initiation of cancer stem cell (CSC) factors. ${ }^{3-5}$ HIF-2a activates signaling pathways such as Oct4 and Notch, which control the self-renewal and multipotency of CSCs. ${ }^{6}$ All of the altered characteristics of tumors may impair effective cancer treatment.
Replication-selective oncolytic adenoviruses are an attractive strategy for cancer therapy because they are able to infect, replicate in and lyse tumor cells. Viruses can be modified in various ways to improve their selectivity and therapeutic efficacy. First, viruses have mutated genes that are essential for viral replication in non-tumor cells but can be selectively compensated by specific cellular mutations in cancer cells.7 Second, the enhancer or promoter region of the E1A gene, which is required for adenovirus replication, can be modified with tumor- or tissuespecific promoters. ${ }^{8-12}$ On these modifications, oncolytic adenoviruses are capable of replicating and lysing tumor cells while sparing non-tumor cells. These viruses have shown acceptable anti-tumor activity and overall safety in various cancers, including bladder cancer. ${ }^{13-15}$ In the past decade, numerous clinical trials have been conducted to assess the potential of oncolytic viruses for cancer therapy. ${ }^{16}$ An oncolytic vaccinia virus, Pexa-Vec (formerly known as JX-594), was engineered to selectively replicate in cells with alterations of the RAS pathway and to express human granulocyte-macrophage colony-stimulating factor (hGM-CSF). Pexa-Vec was employed in clinical trials for the treatment of hepatocellular carcinoma (phase I) and colorectal cancer (phase II). ${ }^{17}$ An oncolytic herpes simplex virus type 1, Talimogene laherparepvec (T-VEC), which was manipulated to express hGM-CSF, has been tested for the treatment of unresected Stage IIIB, IIIC or IV melanoma. Results from the clinical trials indicated that these oncolytic viruses hold promise as anticancer agents. $^{18,19}$

\footnotetext{
${ }^{1}$ Department of Biochemistry and Molecular Biology, National Cheng Kung University Medical College, Tainan, Taiwan; ${ }^{2}$ Department of Nursing, Chung Hwa University of Medical Technology, Tainan, Taiwan; ${ }^{3}$ Department of Urology, Tainan Hospital, Department of Health, Executive Yuan, Tainan, Taiwan; ${ }^{4}$ Department of Microbiology, School of Medicine, China Medical University, Taichung, Taiwan; ${ }^{5}$ Institute of Medical Sciences, Tzu Chi University, Hualien, Taiwan and ${ }^{6}$ Department of Microbiology and Immunology, National Cheng Kung University Medical College, Tainan, Taiwan. Correspondence: Professor C-L Wu, Department of Biochemistry and Molecular Biology, National Cheng Kung University Medical College, 1 University Road, Tainan 70101, Taiwan. or Professor A-L Shiau, Department of Microbiology and Immunology, National Cheng Kung University Medical College, 1 University Road, Tainan 701, Taiwan.
}

E-mail: wumolbio@mail.ncku.edu.tw or alshiau@mail.ncku.edu.tw

${ }^{7}$ These authors contributed equally to this work.

Received 29 April 2014; revised 8 October 2014; accepted 25 November 2014; published online 15 January 2015 
Oct4 is a transcriptional factor that is a key regulator of pluripotency and self-renewal in embryonic stem cells and is also expressed in bladder cancer. ${ }^{20,21}$ We have demonstrated that Oct4 expression reflects tumor progression and regulates motility of bladder cancer cells. ${ }^{11}$ We generated an E1B 55-kDa-deleted adenovirus, designated Ad90C, which is driven by nine copies of the Oct4 response element (ORE) ligated to a human cytomegalovirus minimal (CMVmini) promoter. ${ }^{10}$ In addition to Ad90C, we have also generated another oncolytic adenovirus, named AdWS4, under the control of the Oct4 promoter. ${ }^{11}$ These two Oct4regulated oncolytic adenoviruses can specifically kill bladder cancer cells overexpressing Oct4 and exert potent antitumor activity in animal tumor models. ${ }^{10,11}$

Limited viral replication is one of the major obstacles to reaching a highly therapeutic effect. ${ }^{22} \mathrm{~A}$ level of hypoxia similar to that found within solid tumors reduces the replication of adenoviral vectors by reducing E1A expression and hence oncolytic potentials. ${ }^{23,24}$ Hypoxia has been exploited to drive the replication of oncolytic adenoviruses aiming at increasing therapeutic efficacy for solid tumors exhibiting significant areas of hypoxia. ${ }^{25-27}$ Currently designed oncolytic adenoviruses may require additional modifications to target tumor cells in hypoxic regions. To overcome such drawbacks, in the present study, we generated a new hypoxia-activated oncolytic adenovirus, designated AdLCY, which contains a dual hypoxia/Oct4-responsive promoter composed of the CMVmini promoter ligated with six copies of the HRE and nine copies of the ORE.

Bladder cancer is the most common cancer in the urinary system in the United States. ${ }^{28}$ Progression to or presentation with muscle-invasive disease usually worsens the survival rate of patients and requires more aggressive therapy. Oct4 and Sox2, which are stemness markers expressed in bladder cancer, have been implicated to be responsible for proliferation and differentiation of CSCs and are correlated to disease prognosis. ${ }^{29,30}$ We found that using HRE/ORE segments to transcriptionally regulate adenoviral replication in Oct4-overexpressing cancer cells increased viral replication and oncolytic activities in hypoxic environments, thereby improving antitumor activity against bladder cancer. As Oct4 is expressed in a broad spectrum of cancer and tumor hypoxia increases malignant progression and metastasis, ${ }^{1,31}$ Oct4 and hypoxia dual-regulated oncolytic adenoviruses may be broadly applicable.

\section{RESULTS}

Combination of the CMVmini promoter with $6 \times \mathrm{HRE}$ and $9 \times \mathrm{ORE}$ increased its transcriptional activity in hypoxic bladder cancer cells We first used quantitative real-time reverse transcription (RT)polymerase chain reaction (PCR) analysis to examine Oct4 mRNA levels in various human and murine bladder cancer cells under normoxic and hypoxic conditions. Levels of Oct4 mRNA expression were higher in hypoxic than in normoxic conditions in all the cells tested (Figure 1a). In human bladder cancer cells, hypoxia induced Oct4 mRNA expression by 4- to 23-folds. Accordingly, higher levels of Oct4, HIF-1a and HIF-2a proteins were also detected in these cell lines under hypoxia than under normoxia (Figure 1b). In the murine MBT-2 cell line and its two sublines, hypoxia also induced Oct4 mRNA expression, albeit at lower levels of induction compared with those in human bladder cancer cells (Figure 1a). Regarding protein expression levels, MBT-2 and MBT-2-LM7 cells under hypoxic conditions expressed higher levels a
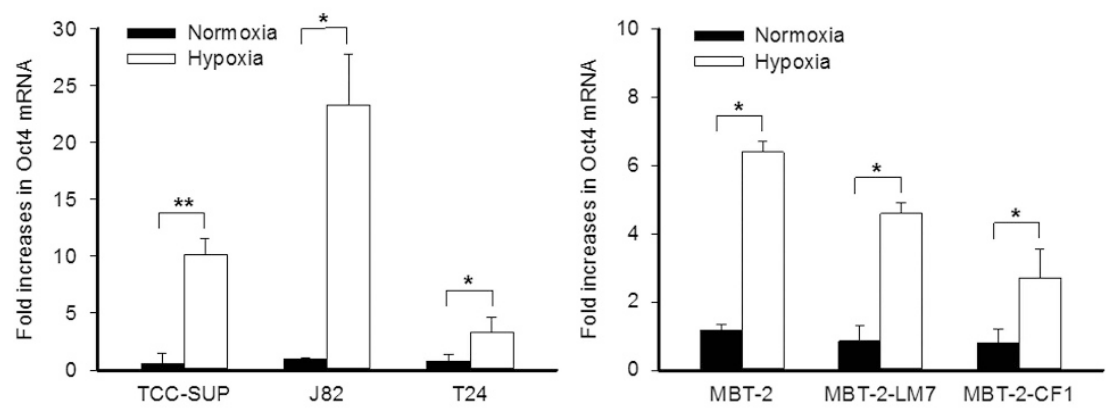

b

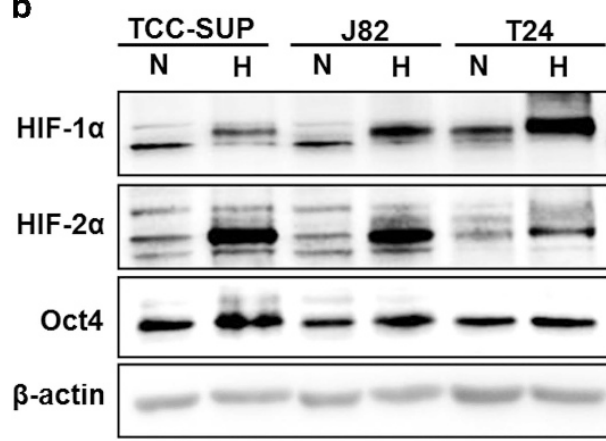

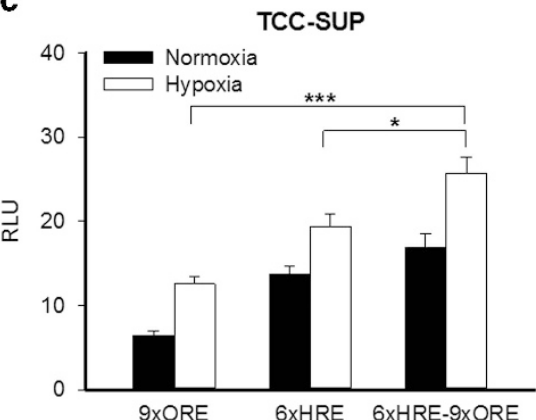

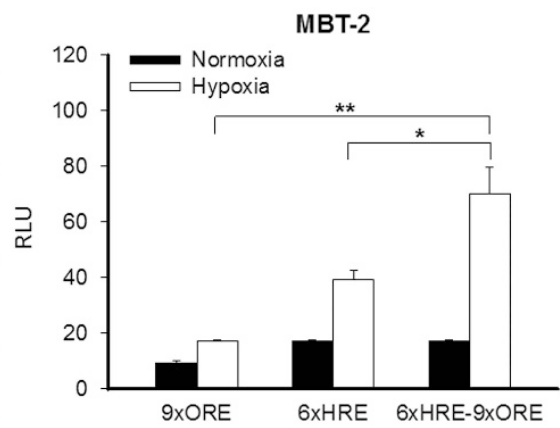

Figure 1. The CMVmini- $6 \times$ HRE-9 $\times$ ORE promoter was highly responsive to endogenous Oct4 and HIFs in hypoxic human and murine bladder cancer cells. (a) Expression of Oct4 mRNA in bladder cancer cells under normoxic and hypoxic conditions for $48 \mathrm{~h}$, as determined by quantitative real-time RT-PCR. (b) Detection of HIF-1 $\alpha$, HIF-2 $\alpha$ and Oct4 expression in bladder cancer cells after exposure to normoxia (N) or hypoxia $(\mathrm{H})$ for $48 \mathrm{~h}$. The expression of $\beta$-actin served as the loading control. (c) Determination of promoter activities. TCC-SUP and MBT-2 cells were transfected with single dual-luciferase reporter constructs, which contained the CMVmini promoter ligated with either $6 \times \mathrm{HRE}$ or $9 \times$ ORE, or both to drive firefly luciferase, as well as the CMV promoter to drive Renilla luciferase, and then exposed to normoxia or hypoxia for $48 \mathrm{~h}$. Promoter activities were determined by a dual-luciferase reporter assay. The ratio of firefly luciferase activity to Renilla luciferase activity was expressed as relative light units $(\mathrm{RLU})(n=4)$. Values are the mean \pm s.e.m. of the mean. ${ }^{* * *} P<0.001 ;{ }^{* *} P<0.01 ;{ }^{*} P<0.05$. 
of Oct4, HIF-1a and HIF-2a proteins than those under normoxic conditions (Figure 1b). However, only HIF-2, but not Oct4 and HIF-1a proteins, was elevated following hypoxic induction (Figure 1b). We next used three different reporter constructs to examine the promoter activities of the CMVmini promoter ligated with either $6 \times \mathrm{HRE}$ or $9 \times \mathrm{ORE}$, or both in hypoxic or normoxic TCC-SUP and MBT-2 cells. As shown in Figure 1c, activities of the three promoters increased when TCC-SUP (upper panel) and MBT-2 (lower panel) cells were under hypoxic conditions. Moreover, the CMVmini promoter ligated with both $6 \times \mathrm{HRE}$ and $9 \times$ ORE exerted higher transcriptional activity than that conjugated with either $6 \times \mathrm{HRE}$ or $9 \times$ ORE. Collectively, these results indicate that the CMVmini- $6 \times \mathrm{HRE}-9 \times$ ORE promoter was highly responsive to endogenous Oct4 and HIFs in hypoxic cells.

Knockdown of HIF-2a suppressed Oct4 expression as well as Oct4and hypoxia-dependent transactivation in bladder cancer cells

As Oct4 has been identified as a HIF-2a-specific target gene, ${ }^{5}$ we next tested whether silencing HIF-2a expression reduces Oct4 expression and thereby decreases the transcriptional activity of the CMVmini-9 $\times$ ORE promoter in hypoxic tumor cells. TCC-SUP and MBT-2 cells that have been transfected with a reporter construct containing the CMVmini- $9 \times$ ORE promoter were transfected with short hairpin RNA (shRNA) constructs specific to HIF-2a (shHIF-2a) or green fluorescent protein (GFP) (shGFP) for $24 \mathrm{~h}$ and then exposed to hypoxia or normoxia for additional $24 \mathrm{~h}$. Knockdown of HIF-2a expression resulted in decreased Oct4 expression in TCC-SUP (Figure 2a, left panel) and MBT-2 (Figure 2b, left panel) cells under hypoxic conditions. Furthermore, the transcriptional activity of the CMVmini-9 $\times$ ORE was also downregulated in hypoxic TCC-SUP (Figure 2a, right panel) and MBT-2 (Figure 2b, right panel) cells after transduction with shRNA specific to HIF-2a. These results confirmed that HIF-2a is involved not only in HRE-dependent transactivation, but also regulates Oct4 transactivation. Given that the transcriptional activity of the CMVmini- $6 \times$ HRE- $9 \times$ ORE promoter was higher than that of the CMVmini-9 $\times$ ORE promoter (Figure 1c), we generated AdLCY, which is an Oct4 and hypoxia dual-regulated oncolytic adenovirus, by adding six copies of the HRE upstream of the CMVmini- $9 \times$ ORE for driving adenovirus E1A gene expression in the context of the E1B 55-kDa-deleted adenovirus Ad9OC. ${ }^{10}$

AdLCY exerted higher tumor-selective cytolytic activity against hypoxic bladder cancer cells than Ad90C

The Oct4-dependent oncolytic adenovirus Ad90C, which was derived from the E1B-55-kDa-deleted oncolytic adenovirus Ad5WS1, was constructed under the transcriptional control of $9 \times$ ORE-CMVmini promoter. ${ }^{32}$ To further construct an Oct4 and hypoxia dual-regulated oncolytic adenovirus, the promoter of Ad9OC was replaced with $6 \times \mathrm{HRE}$ and $9 \times$ ORE-CMVmini promoter to generate AdLCY (Figure 3a). The cytolytic effects of AdLCY and Ad9OC on TCC-SUP cells were compared (Figure 3b). While Ad90C induced similar degrees of cytopathic effects (CPE) in cells regardless of hypoxic exposure, the degree of CPE induced by AdLCY was $\sim 10$-fold greater under hypoxic than normoxic conditions in both TCC-SUP and MBT-2 cells, as assessed by crystal violet staining. Furthermore, complete cytolysis was seen in TCC-SUP and MBT-2 cells infected with AdLCY at doses as low as 1 multiplicity of infection (MOI) under hypoxic conditions. In marked contrast, AdLCY failed to induce evident CPE in normal epithelial cells, including human SV-HUC-1 and murine NMuMG cells, even at high MOls.

Efficient adenovirus infection requires the coxsackievirus and adenovirus receptor (CAR), a major receptor of adenovirus serotype 5 for virus attachment and internalization to enter host cells. $^{33-35}$ To determine the infectivity of AdLCY in bladder cancer cells, we tested the expression of CAR by flow cytometric analysis
(Figure 4a). Our results revealed that CAR expression was detected in both human bladder cancer cells ( $82.45 \%$, TCC-SUP) and normal urothelial cells $(34.63 \%$, SV-HUC-1). Murine bladder cancer cells (MBT-2) and normal murine mammary gland epithelial cells (NMuMG) also expressed CAR (9.68 and 19.04\%, respectively), albeit at lower levels than human cells. To assess the susceptibility of cells to adenoviral infection, we used replication-defective adenoviral vectors expressing GFP (AdGFP) to infect these cells and detect GFP expression after $48 \mathrm{~h}$. Figure $4 \mathrm{~b}$ shows that all of the four cell lines could be infected by AdGFP, with human cells more susceptible than murine cells, indicating that both human and murine non-tumor and tumor cells could be infected by adenoviruses. Furthermore, cell susceptibility to adenoviral infection was positively correlated with the surface expression level of CAR. The tumor-specific cytolysis observed in AdLCY was governed by dual-regulation of Oct4 and hypoxia. We used the colorimetric WST-1 assay to compare the survival of bladder cancer and normal cells after infection with AdLCY or Ad90C. As shown in Figure 4c, AdLCY exerted higher cytolytic activities against TCC-SUP and MBT-2 cells under hypoxic than normoxic conditions. Of note, under hypoxic conditions, AdLCY was more effective than Ad9OC against both cancer cells. Furthermore, TCCSUP cells were more sensitive to AdLCY- and Ad90C-induced cytolysis than MBT-2 cells. Although murine MBT-2 cells expressed low levels of CAR, they were also susceptible to adenovirus infection, and AdLCY and Ad9OC could replicate in the cells and induce cytolysis. These results are in accordance with our previous findings that MBT-2 cells could produce adenoviral late proteins, indicative of productive replication, after infection with oncolytic adenoviruses, albeit to a lesser extent than human tumor cells. ${ }^{10}$ Although normal human SV-HUC-1 and murine NMuMG cells could be infected by AdGFP (Figure 4b), they were resistant to cytolysis induced by either AdLCY or Ad9OC (Figure 4C). Taken together, these results indicate that AdLCY selectively killed bladder cancer cells, in particular hypoxic tumor cells, while sparing normal cells.

AdLCY had higher antitumor activity than Ad9OC in mice bearing human bladder tumor xenografts or syngeneic bladder tumors

Compared with Ad90C, AdLCY was more effective in inhibiting tumor growth (Figure 5a) and prolonging survival (Figure $5 \mathrm{~b}$ ) in mice bearing human TCC-SUP tumor xenografts. Similar antitumor effects of AdLCY were also observed in the MBT-2 syngeneic tumor model (Figures $5 \mathrm{c}$ and $\mathrm{d}$ ). We next used immunohistochemical staining to examine the in vivo targeting efficacy of AdLCY in TCC-SUP tumor-bearing mice (Figure 5e). Thirty-one days after tumor cell injection, HIF-1a was detected abundantly, indicating the size of hypoxic regions within tumors became larger along with tumor growth. Compared with tumors infected with AdLacZ, which is a replication-defective adenoviral vector encoding $\beta$-galactosidase, adenoviral proteins were detected abundantly in AdLCY- and Ad9OC-infected tumors, indicative of productive replication of both viruses in hypoxic bladder tumors. Notably, more AdLCY targeted tumor tissue in hypoxic regions, especially in cells that expressed the CSC markers CD44 and CD133. Collectively, these results indicate that the oncolytic efficacy of AdLCY was superior to that of Ad9OC through more efficacious targeting of hypoxic tumors and CSCs.

\section{AdLCY targeted more CD44- and CD133-positive bladder tumor} cells than Ad90C

CD44 and CD133 are major CSC markers, and numbers of CD44and CD133-positive tumor cells usually increase in hypoxic tumor tissues. When TCC-SUP cells were infected with AdLacZ, which was replication-defective, and exposed to hypoxic conditions, the percentages of CD44- and CD133-positive cells rose from 75.92 to $88.10 \%$ (Figure 6a) and from 2.32 to $13.23 \%$ (Figure 6b), 
a

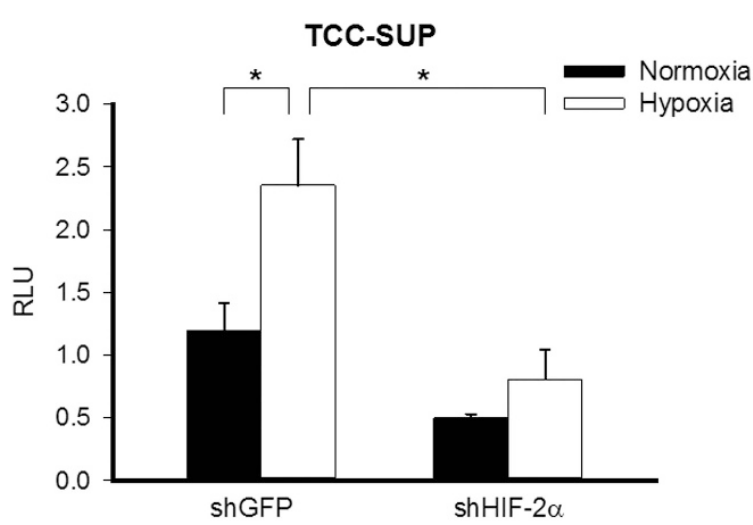

b

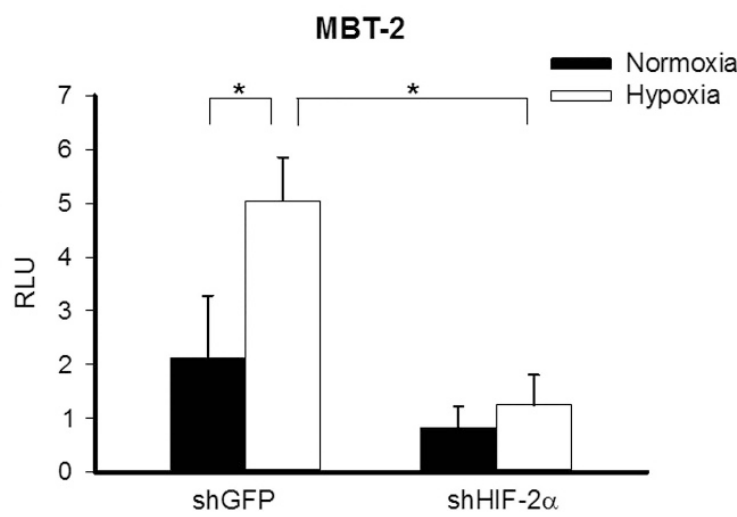

Figure 2. Knockdown of HIF-2 $\alpha$ suppressed Oct4 expression as well as Oct4- and hypoxia-dependent transactivation in bladder cancer cells. TCC-SUP and MBT-2 cultured in six-well plates were transfected with $5 \mu \mathrm{g}$ of shRNA constructs specific to HIF-2 $\alpha$ or GFP. After being cultured for 3 days, the cells were exposed to hypoxia or normoxia for 48 h, followed by immunoblot analysis. Expression of HIF-2 $\alpha$ and Oct 4 in HIF-2 $\alpha$ knockdown TCC-SUP (a, left) and MBT-2 (b, left) cells was detected. The expression of $\beta$-actin served as the loading control. In another set of experiments, cells transfected with shRNA constructed as described above for $24 \mathrm{~h}$ were re-seeded in 24 -well plates and cultured overnight, followed by transfection with $1 \mu \mathrm{g}$ of pFRL2-9 $\times$ ORE-CMVmini, which drives firefly luciferase by the CMVmini promoter ligated with $9 \times$ ORE and drives Renilla luciferase by the CMV promoter contained in the plasmid backbone. After $24 \mathrm{~h}$, the cells were exposed to hypoxia or normoxia for $48 \mathrm{~h}$. Transcriptional activities of the CMVmini promoter ligated with $9 \times$ ORE in TCC-SUP (a, right) and MBT-2 (b, right) cells under normoxia or hypoxia were determined by a dual-luciferase reporter assay. The ratio of firefly luciferase activity to Renilla luciferase activity was expressed as relative light units (RLU) $(n=4)$. Values are the mean \pm s.e.m of the mean. ${ }^{*} P<0.05$.

respectively. These data indicate that hypoxia induced the formation of much more CD133-positive cells than CD44positive cells. Both Ad9OC and AdLCY targeted hypoxic tumor cells. After viral infection at an $\mathrm{MOI}$ of 1 , the percentages of surviving CD44-positive cells (AdLCY: $32.21 \%$ versus Ad90C: 48.99\%) (Figure 6a) and CD133-positive cells (AdLCY: 3.18\% versus Ad90C: $6.35 \%$ ) (Figure 6b) decreased. CSCs that display selfrenewal capability in tumors are responsible for the re-growth and metastasis of tumors after anticancer therapy. We next examined the self-renewal capability of TCC-SUP cells after infection with various adenoviruses in vitro by the soft-agar colony formation assay (Figure $6 c$, upper panel) and quantified numbers of colonies (Figure 6c, lower panel). Consistent with the results shown in Figure 6a, cells infected with AdLaZ, which was non-cytolytic, produced more colonies under hypoxia than under normoxia, indicating that hypoxia was responsible for altering cellular phenotypes by increasing self-renewal capability. Cells infected with either Ad9OC or AdLCY produced smaller colonies than those infected with AdLacZ. Notably, cells infected with AdLCY produced less colonies under hypoxic than under normoxic conditions. Moreover, under normoxic conditions, cells infected with either AdLCY or Ad9OC also produced less colonies than those infected with AdLacZ. These results indicate that AdLCY and Ad9OC could suppress the self-renewal capability of TCC-SUP cells either under hypoxic or normoxic conditions. As Ad90C was transcriptionally regulated by the ORE, but not by the HRE, it was anticipated that no significant differences were found in the numbers of colonies obtained from cells infected with Ad9OC and grown in hypoxic and normoxic conditions. Collectively, these results suggest that, under hypoxic conditions, AdLCY suppressed the self-renewal capability of bladder cancer cells through more effective killing of CD44- and, in particular, CD133-positive tumor cells. Immunofluorescence staining of tumor tissue sections also indicates that AdLCY was more efficacious than $\mathrm{Ad} 90 \mathrm{C}$ at targeting tumors and hypoxic CSCs (Figure 6d). Immunofluorescence double staining shows that AdLCY targeted CD133-positive cells in tumors. CD133 and adenovirus hexon proteins were colocalized in some areas within tumor tissue.

\section{DISCUSSION}

Oxygen deprivation often occurs during tumorigenesis, and it usually changes the microenvironment within tumors. HIFs, such as HIF-1a and HIF-2a, are associated with resistance to chemotherapy and radiotherapy. Along with tumor progression, these transcriptional factors activate a series of regulatory programs, enhance metastasis and initiate the generation of CSCs. These changes therefore become a major challenge for successful cancer treatment. ${ }^{36-38}$ We previously showed that downregulation of HIF-1a expression inhibited lung tumor growth through an anti-angiogenesis mechanism. ${ }^{39}$ Nevertheless, cytolytic effects of oncolytic viruses are usually attenuated in a hypoxic 
a

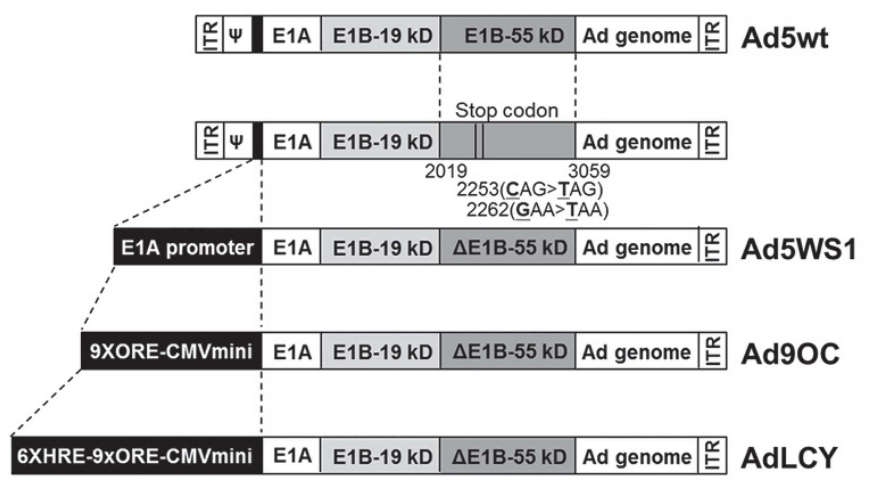

b

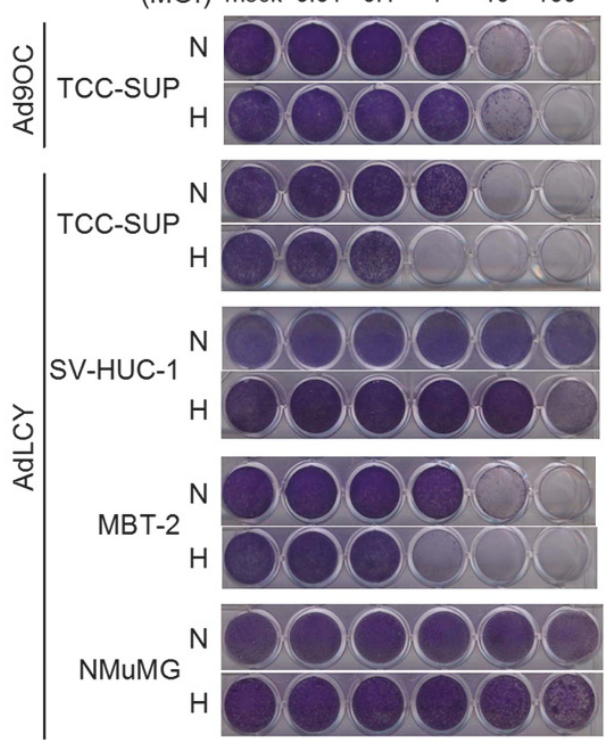

Figure 3. AdLCY displayed potent cytolytic activity against hypoxic bladder cancer cells while sparing normal cells. (a) Schematic diagram showing the genome organization of three recombinant adenoviruses, Ad5WS1, Ad9OC and AdLCY, as well as wild-type adenovirus type 5 (Ad5wt). Two point mutations were made at bases 2253 (C-T) and 2262 (G-T) of the E1B-55 kD gene (nucleotide 2019-3059) of Ad5 to generate premature translation stop codons, resulting in Ad5WS1, an E1B-55 kD-deleted adenovirus driven by the E1A promoter. ITR, inverted terminal repeat; $\psi$, packaging signal. Numbers indicate nucleotide positions of Ad5. The E1A promoter was replaced with $9 \times$ ORE-CMVmini and $6 \times$ HRE-9 $\times$ ORE -CMVmini promoters to generate Ad9OC and AdLCY, respectively. (b) Virus-induced CPE. Bladder cancer (TCC-SUP and MBT-2) and normal epithelial (SV-HUC-1 and NMuMG) cells were infected with increasing MOls of AdLCY or Ad9OC, or were mock-infected under normoxia $(\mathrm{N})$ or hypoxia $(\mathrm{H})$ for $48 \mathrm{~h}$. Cells were then cultured in normoxic conditions for 5 days, and the CPE was visualized by crystal violet staining.

environment. In the present study, to increase their cytolytic effects, we added six copies of HRE to the regulatory region of Ad90C, which is regulated by Oct $4,{ }^{10}$ and generated a novel Oct4 and hypoxia dual-regulated AdLCY. We found that an oncolytic virus driven by six copies of the HRE was highly responsive to hypoxia. We have previously shown that reporter constructs carrying six copies of the HRE conferred higher hypoxic responsiveness than those carrying three copies, and that a saturation effect occurred with more than six copies, indicating six copies of the HRE upstream of the CMVmini promoter resulted in maximal hypoxia-inducible gene expression. ${ }^{40}$ Transcriptional activity was even higher in a hypoxic environment when oncolytic adenoviruses were driven by the combination of $6 \times \mathrm{HRE}$ and $9 \times$ ORE than when they were under the control of either $6 \times \mathrm{HRE}$ or $9 \times$ ORE alone. Notably, AdLCY had no cytolytic effects on nontumor cells. We showed that CAR was expressed on the cell surface of both human normal urothelial cells and murine mammary gland epithelial cells. Nevertheless, based on our previous ${ }^{9}$ and current studies, AdLCY failed to replicate in and consequently lyse these non-tumor cells, despite being able to infect them, as evidenced by GFP expression after infection with AdGFP. The tumor specific cytolysis observed in AdLCY was governed by dual-regulation of Oct- 4 and hypoxia. As HREs are present on the Oct4 promoter, HIF-2a can activate the expression of Oct4. ${ }^{5}$ Furthermore, HIF-2 $a$ and Oct4 bind directly to the $6 \times$ HRE and $9 \times$ ORE, respectively, thus enhancing the replication capability of AdLCY and allowing the virus to efficiently target tumor cells. This dual-regulated mechanism may be attributed to a greater oncolytic activity of AdLCY in comparison with Ad90C.

During tumor invasion, hypoxia-associated factors switch cells from an HIF-1a-dependent to an HIF-2a-dependent signaling pathway and promote the formation of CSC characteristics. ${ }^{41}$ One of the essential stemness markers activated by HIF-2a is Oct $4{ }^{5}$ which acts with other stem cell factors, such as Lin28, to increase CSC proliferation. ${ }^{42}$ CSCs are a subpopulation of tumor cells that augment tumorigenesis in specific tumor microenvironments. Self-renewal and differentiation are two hallmark traits of CSCs. The existence of highly tumorigenic CSCs might be responsible for the initiation and progression of numerous aggressive epithelial cancers into locally invasive, metastatic and incurable disease states. ${ }^{43,44}$ CSCs have also been identified in human bladder cancer tissues. ${ }^{45,46}$ Potential therapeutic targets to eradicate CSCs are being developed and showing promising results against locally advanced and metastatic cancers, ${ }^{47}$ including the inhibition of the HIF pathway. ${ }^{48}$ Consistent with these findings, our results show that HIF-2a shRNA inhibited the expression of Oct4 and its transactivational activity (Figure 2).

In the present study, while in hypoxic J82 and TCC-SUP cells, Oct4 mRNA was induced 23- and 10-folds, respectively, and their Oct4 protein expression was significantly elevated, Oct4 mRNA was only induced 5-fold and Oct4 protein expression was slightly increased in hypoxic T24 cells (Figures 1 and 2). As HIF-2a can activate Oct4 signaling pathways, ${ }^{6}$ lower expression of HIF-2a in T24 cells in response to hypoxia might account for lower Oct4 gene expression. Of note, unlike Oct4 expression patterns in parental MBT-2 cells, expression of Oct4 in MBT-2-CF1 cells was increased at the mRNA, but not at the protein level under hypoxia. MBT-2-CF1 was a subline derived from MBT-2 cell line by in vivo passages of MBT-2 cells in our laboratory. MBT-2-CF1 cells exhibited increased tumorigenic potential in mice. Therefore, genetic alterations in MBT-2-CF1 cells during in vivo passages may have occurred and account for the discrepant expression of Oct4. However, additional study is needed to further characterize MBT-2-CF1 cells.

In the present study, we also found that AdLCY targeted CD44and CD133-positive cells. CD44 and CD133 are both transmembrane proteins and surface markers for CSCs. CD44 generally acts as a specific receptor of hyaluronic acid, promotes cell migration and is usually highly expressed in almost all cells. A gene ontology analysis showed that more than one-third of the CD133-upregulated genes 
a

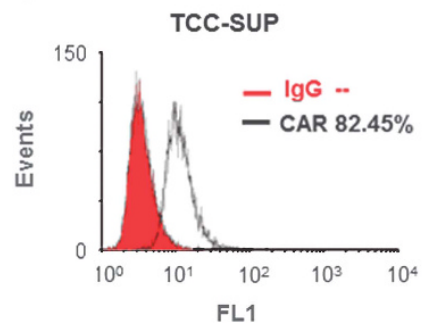

SV-HUC-1

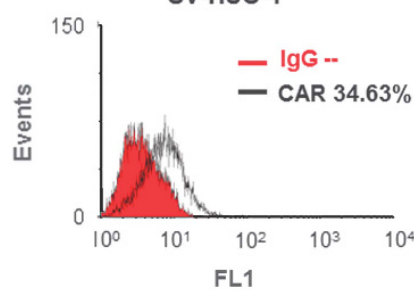

MBT-2

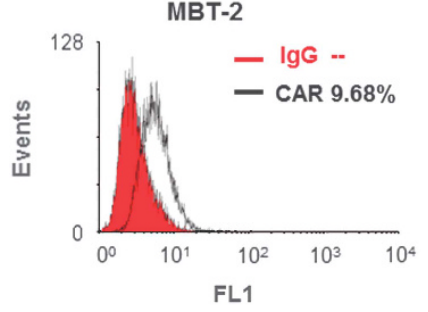

NMUMG

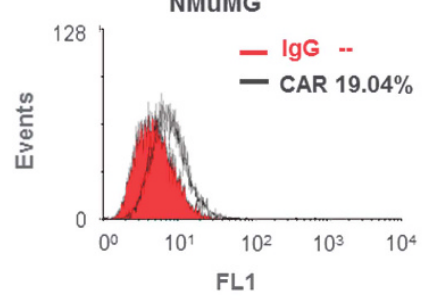

b
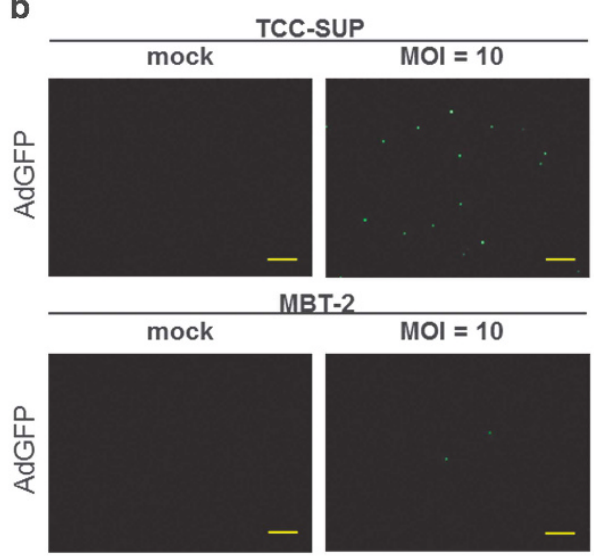

TCC-SUP

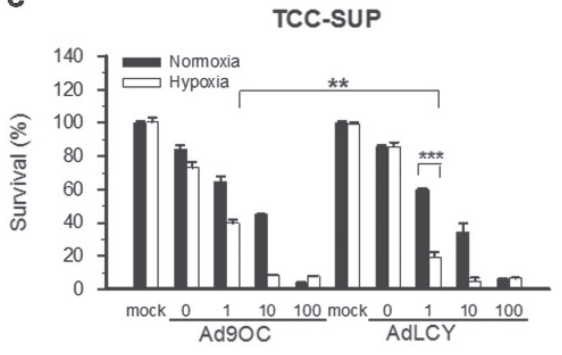

MBT-2

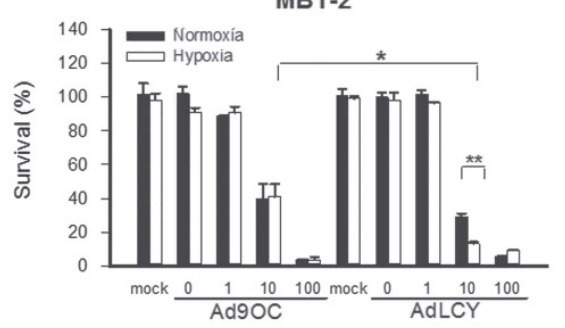

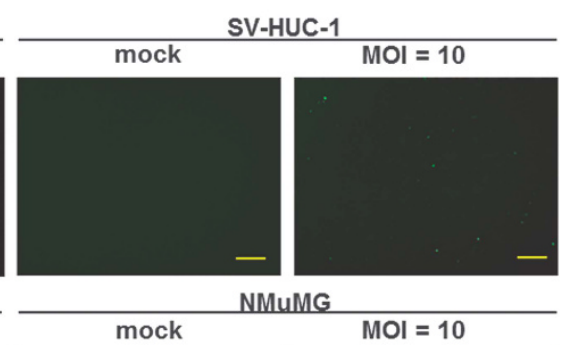
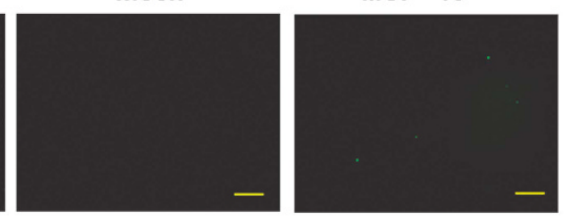

SV-HUC-1

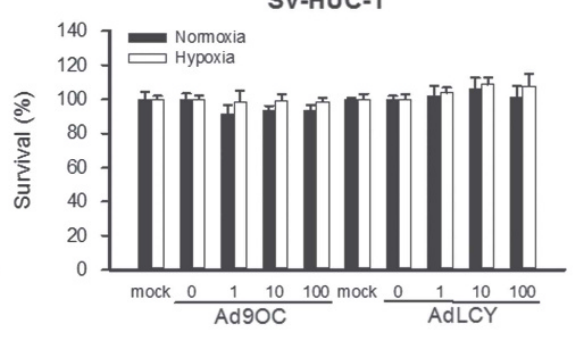

NMuMG

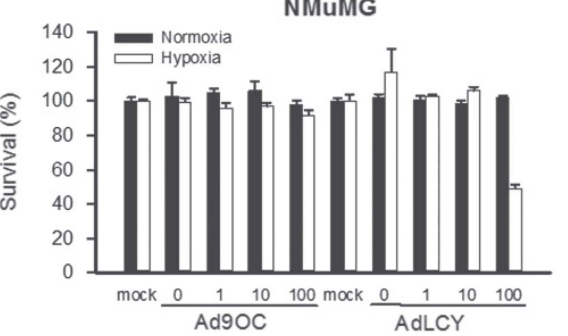

Figure 4. AdLCY exhibited higher tumor-selective cytolytic effect than Ad9OC on bladder cancer cells. (a) Analysis of surface expression of CAR on bladder cancer and normal epithelial cells by flow cytometry. Black lines denote cell percentages expressing CAR. Red zones represent background fluorescence on the cells. (b) Detection of AdGFP-infected cells. Various cells were infected with AdGFP at an MOI of 10 or mock-infected for $48 \mathrm{~h}$. Cells expressing GFP were observed under fluorescence microscopy. Representative images in each group are shown $(\times 40$ magnification; scale bar $=500 \mu \mathrm{m})$. (c) Cytotoxic effects of AdLCY and Ad9OC. Bladder cancer and normal epithelial cells were infected with increasing MOls of AdLCY or Ad90C, or were mock-infected under normoxia $(\mathrm{N})$ or hypoxia $(\mathrm{H})$ for $48 \mathrm{~h}$. Cells were then cultured in normoxic conditions for 5 days, and cell survival was determined by the WST- 1 assay. Values are the mean \pm s.e.m. of the mean. ${ }^{* * *} P<0.001$; ${ }^{*} P<0.01 ; * P<0.05$.

are involved in the cell cycle process and a certain number of CD133-downregulated genes are involved in the immune response. ${ }^{49}$ The CD133-related gene expression signature identifies aggressive glioblastoma subtypes as well as high-grade bladder and breast cancers. ${ }^{49}$ Therefore, cancers originating from distinct tissue types may share some fundamental properties at the stem-cell level. For these reasons, CD133 provides a pivotal molecular target for cancer treatment, especially for more invasive tumors. However, the sparseness of CD133-positive cells in bladder cancer tumors makes targeting their cells challengeable. It was shown that overexpression of HIF-1a and HIF-2a activates the CD133 promoter through ETS proteins. ${ }^{50}$ Therefore, multiple onco-targets (including Oct4 and CD133) of hypoxiainducible factors suggest that HIFs are master regulators of stemness properties of cancer-initiating cells and also serve as potential therapeutic targets. As a hypoxic-dependent oncolytic virus, AdLCY may be more efficacious than Ad9OC at targeting CSC cells.

AdLCY can replicate in a hypoxic environment. Tumors are not capable of growing beyond a certain size without angiogenesis because of the limited diffusion of oxygen. When the volume of a solid tumor is $>1 \mathrm{~mm}^{3}$, tumor cells would be faced with hypoxia. ${ }^{51}$ An in vivo ${ }^{31} \mathrm{P}$ nuclear magnetic resonance (NMR) spectroscopy has estimated that $\sim 4 \%$ of the hypoxic cell fraction occurred in tumors $<100 \mathrm{~mm}^{3}$, and the fraction increased to $40 \%$ when tumor volume grew to $250 \mathrm{~mm}^{3}{ }^{52}$ For these reasons, in our animal model, when visible and palpable nodules (mean tumor volume: $41.51 \pm 7.70 \mathrm{~mm}^{3}$; range: $8.81-117.07 \mathrm{~mm}^{3}$ ) developed at all injection sites on day 21 , we injected the tumors with oncolytic adenoviruses on days 21, 23 and 25. We found that, compared with injections of saline and Ad90C, intratumoral injections of AdLCY significantly retarded tumor growth in mice with subcutaneous TCC-SUP tumors. Mouse survival after AdLCY treatment was also significantly prolonged. The mean tumor volume on day 26 was $185.03 \mathrm{~mm}^{3}$ in the saline-treated control group. When hypoxic areas expanded within tumors at this stage, tumoricidal effects of hypoxia-independent oncolytic adenoviruses might be attenuated. The emergence of CSCs following hypoxia promotes cancer progression and metastasis. Indeed, we also found metastatic nodules in the lungs at day 61 
a

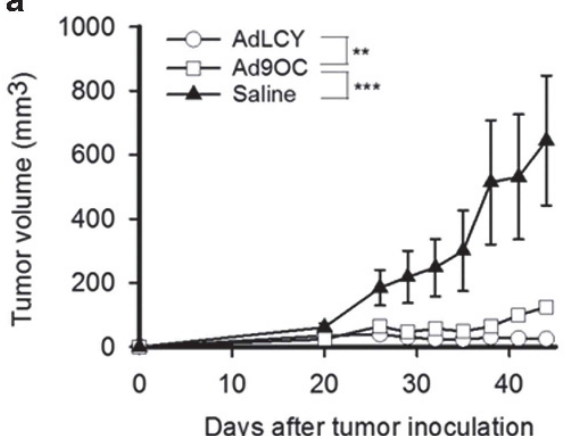

c

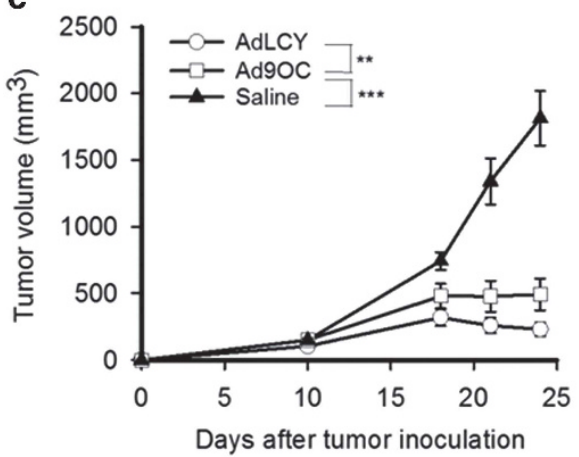

b

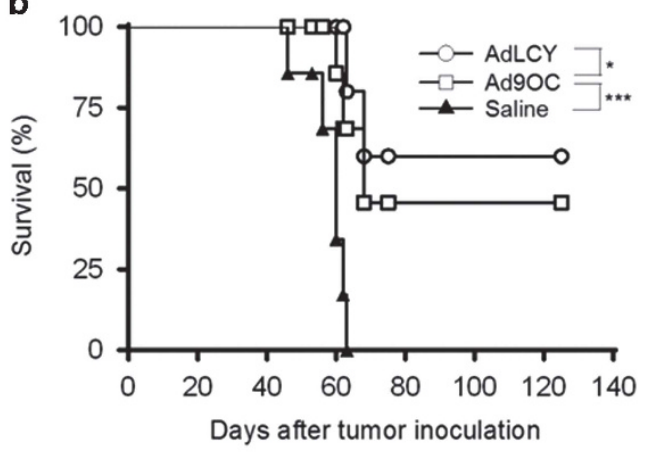

d

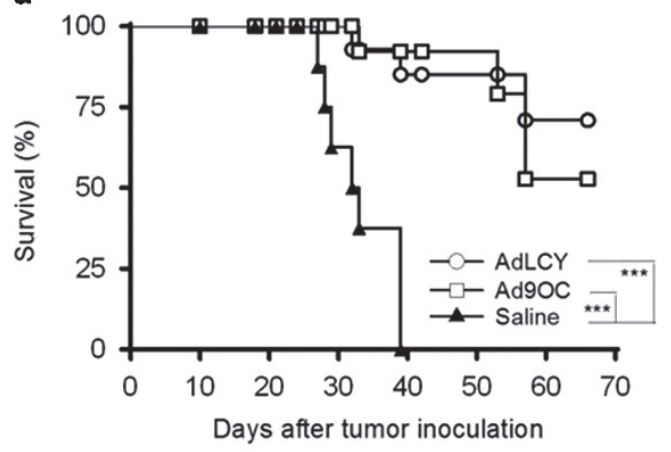

e

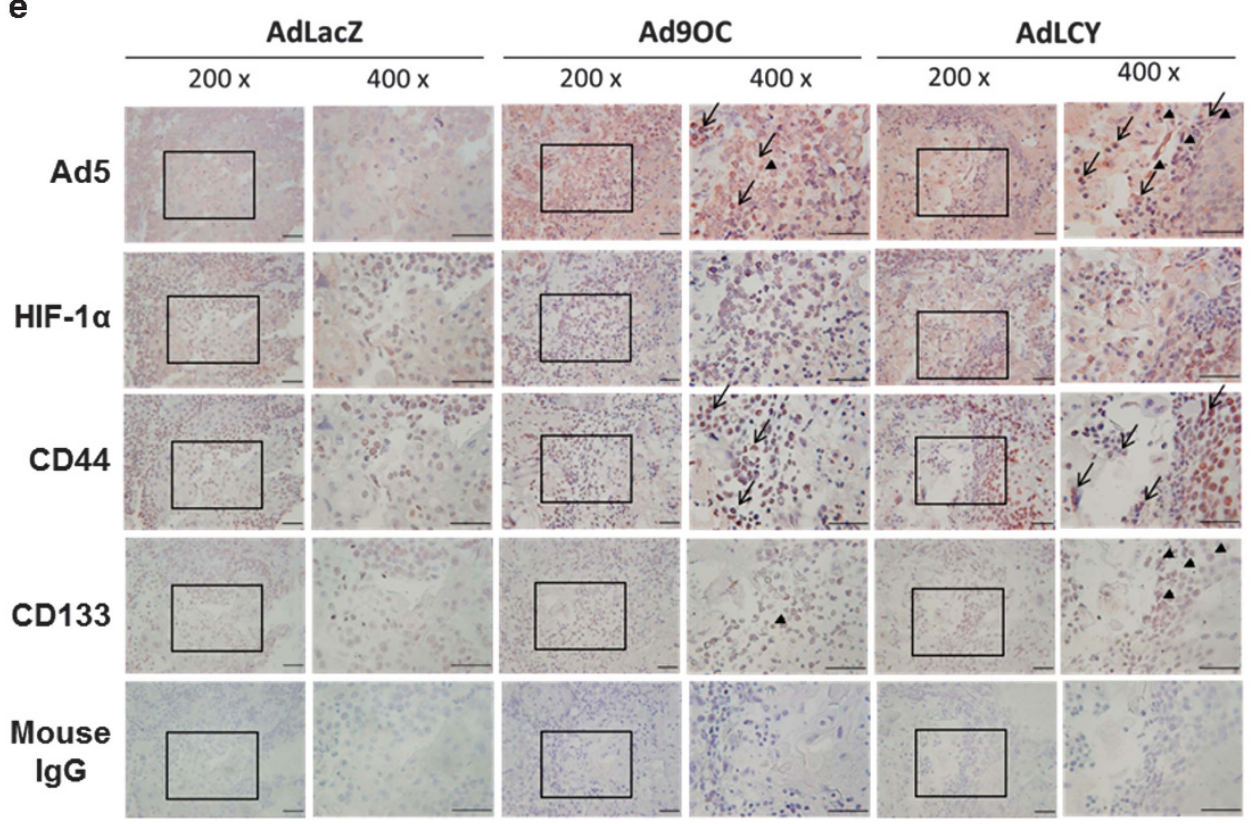

Figure 5. AdLCY had higher oncolytic activity than Ad9OC against TCC-SUP xenografts and syngeneic MBT-2 tumors. (a, b) Groups of NOD/ SCID mice $(n=5-6)$ were subcutaneously inoculated with TCC-SUP cells $\left(5 \times 10^{6}\right)$ on day 0 , and intratumorally treated with $5 \times 10^{8}$ PFU of AdLCY or Ad90C, or with saline on days 21, 23 and 25. Tumor volumes (a) and Kaplan-Meier survival curves (b) were determined. (c, d) Groups of $\mathrm{C} 3 \mathrm{H} / \mathrm{HeN}$ mice $(n=8)$ were subcutaneously inoculated with MBT-2 cells $\left(5 \times 10^{6}\right)$ on day 0 , and intratumorally treated with $5 \times 10^{8}$ PFU of AdLCY or Ad9OC, or with saline on days 11,13 and 15. Tumor volumes (c) and Kaplan-Meier survival curves (d) were determined. Values are the mean \pm s.e.m. of the mean. ${ }^{* *} P<0.001 ;{ }^{* *} P<0.01 ;{ }^{*} P<0.05$. (e) NOD/SCID mice were inoculated with TCC-SUP cells and then treated with AdLCY, Ad9OC or AdLacZ as described in a, tumors were excised on day 31, and serial formalin-fixed paraffin sections of tumor tissues were immunohistochemically stained for adenovirus type 5 (Ad5) proteins, HIF-1 $\alpha$, CD44 and CD133. Representative images in each group are shown (scale bar $=50 \mu \mathrm{m}$ ). Images shown at $\times 400$ magnification correspond to the boxed areas in the images shown at $\times 200$ magnification. Colocalization of Ad5 with CD44 and with CD133 is indicated by arrows and arrowheads, respectively. Background staining was determined by substituting isotype control IgG for the primary antibody. 
a
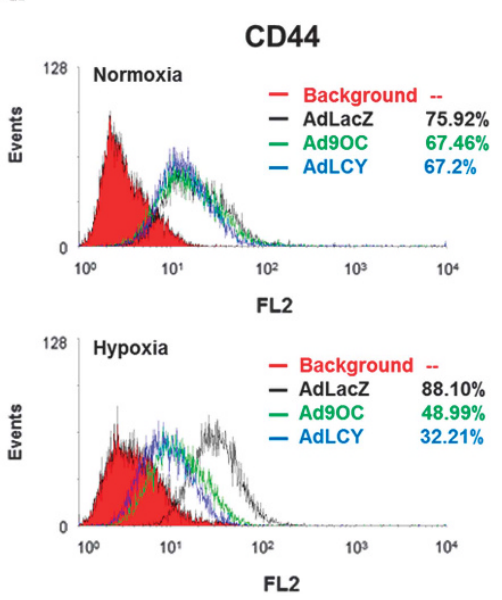

d
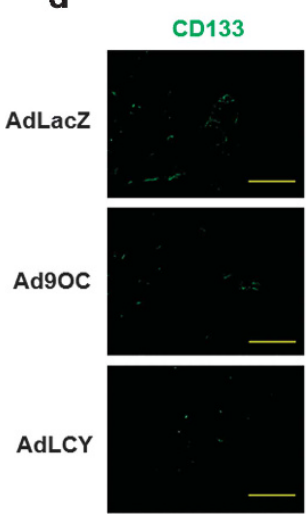

b
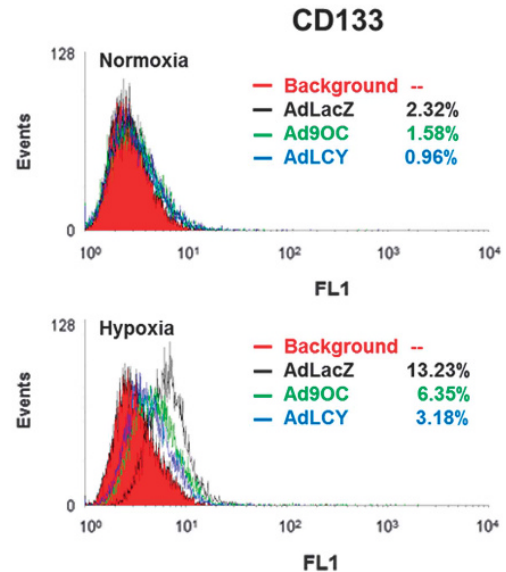

C

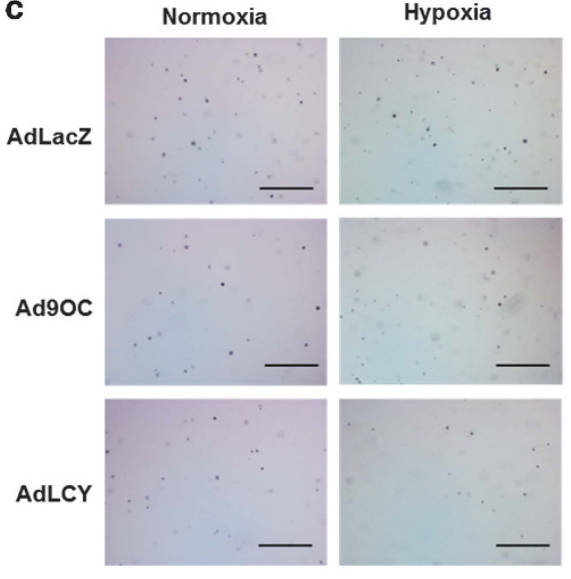

Figure 6. AdLCY targeted more CD44- and CD133-positive bladder tumor cells than Ad90C. (a, b) Detection of cells expressing CD44 and CD133 after viral infection. TCC-SUP cells were infected with AdLCY, Ad9OC or AdLacZ at an MOI of 1 for 5 days. Intensities of CD44 (a) and CD133 (b) expression on surviving cells after viral infection were analyzed by flow cytometry. Black, green and blue lines denote cell percentages after AdLacZ, Ad9OC and AdLCY infection, respectively; red zones represent background fluorescence on the cells. (c) Self-renewal capability of bladder cancer cells after viral infection under hypoxic or normoxic conditions. TCC-SUP cells infected with various adenoviruses at an $\mathrm{MOI}$ of 1 were cultured under hypoxic or normoxic conditions for $48 \mathrm{~h}$. Cells were then grown on soft agar, and cell colonies were observed and counted after 24 days. Representative images for colonies grown in soft agar in each group are shown ( $\times 40$ magnification; scale bar $=500 \mu \mathrm{m}$, upper panel). The number of colonies in each group was quantified (lower panel). Each group was performed in triplicate. Results are representative of three independent experiments. Values are the mean \pm s.e.m. of the mean. ${ }^{* * *} P<0.001 ;$ ${ }^{*} P<0.01 ;{ }^{*} P<0.05$. (d) Immunofluorescence double staining showing targeting of AdLCY to CD133-positive cells in bladder tumors. NOD/ SCID mice bearing TCC-SUP tumors $(n=5)$ were intratumorally treated with $5 \times 10^{8}$ PFU of AdLCY, Ad9OC or AdLacZ on days 21,23 and 25 , and then killed on day 31. Representative images in each group are shown ( $\times 400$ magnification; scale bar $=50 \mu \mathrm{m})$. Magnified images correspond to the boxed areas in the merged images. Colocalization of Ad5 hexon proteins with CD133 is indicated by arrows. The nucleus was counterstained with DAPI.

after tumor cell inoculation in our subcutaneous bladder tumor models. Therefore, more effective targeting of AdLCY to CSCs and tumor cells in a hypoxic environment may account for its potent antitumor effects. However, most of the CSC models that have been studied rest on experimental foundations. Different characteristics of CSCs within tumors reflect different cancer types and hosts used. ${ }^{53}$ Thus, further investigation of the characteristics of CSCs that increase in hypoxic areas of different tumors during tumor progression would be of great help in designing ideal oncolytic adenoviruses with potent antitumor activity.

In conclusion, we have developed AdLCY, an Oct4 and hypoxia dual-regulated oncolytic adenovirus, which is potent and efficacious for treating hypoxic bladder tumors in animal models. As hypoxia and CSCs are hallmarks of tumor growth and progression, AdLCY may be broadly exploited for treating a wide range of primary and metastatic tumors.

\section{MATERIALS AND METHODS}

\section{Cells and mice}

Human bladder cancer (TCC-SUP, J82 and T24) and murine bladder cancer (MBT-2) cell lines, as well as immortalized normal human urothelial cell line (SV-HUC-1) and normal murine mammary gland epithelial cell line (NMuMG), have been previously described. ${ }^{10}$ MBT-2-LM7 (lung-metastatic MBT-2 clone 7) was derived from a metastatic lung nodule after subcutaneous implantation of MBT-2 tumors in $\mathrm{C} 3 \mathrm{H} / \mathrm{HeN}$ mice. ${ }^{10} \mathrm{~A}$ subline of the MBT-2 cell line, designated MBT-2-CF1, was derived from in vivo passages of parental MBT-2 cells, which resulted in increased tumorigenicity in $\mathrm{C} 3 \mathrm{H} / \mathrm{HeN}$ mice. All cells were cultured in Dulbecco's modified eagle's medium (DMEM) supplemented with $2 \mathrm{~mm}$ L-glutamine, $10 \%$ cosmic calf serum (Hyclone, Logan, UT, USA) and $50 \mathrm{mg} \mathrm{m}^{-1}$ gentamicin. Female NOD/SCID mice (6-8 weeks old) were purchased from the Laboratory Animal Center of National Cheng Kung University. The experimental protocol adhered to the rules of the Animal Protection Act of Taiwan and was approved by the Laboratory Animal Care and Use Committee of National Cheng Kung University. 
Hypoxic conditions for cell culture

Hypoxia was achieved using a hypoxia chamber (GasPak EZ Anaerobe Container System; Becton Dickinson, Sparks, MD, USA) with three sachets (GasPak EZ Anaerobic System Sachets; Becton Dickinson) and one anaerobic indicator strip (GasPak EZ Anaerobic System with indicator; Becton Dickinson). The container was then incubated at $37^{\circ} \mathrm{C}$. After $2.5 \mathrm{~h}$, the percent of oxygen was less than or equal to $1 \%$. The in vitro studies were then carried out in the chamber, and the anaerobic indicator strip was used to monitor the percentage of oxygen during all experiments performed to confirm hypoxic conditions.

\section{Analysis of promoter activities}

DNA fragments containing nine copies of tandemly repeated sequences of ORE $(9 \times \mathrm{ORE})$ and the CMVmini promoter derived from pTRE vector (Clontech, Mountain View, CA, USA) were placed upstream of the luciferase gene of the single dual-luciferase reporter plasmid $\mathrm{pFRL} 2^{54}$ to generate pFRL2-9 $\times$ ORE-CMVmini. ${ }^{10}$ The pFRL2 plasmid carries firefly luciferase gene driven by the tested promoter cloned upstream of the gene as well as Renilla luciferase gene driven by the CMV promoter. Rather than using a test reporter plasmid and a control reporter plasmid to normalize transfection efficiency in reporter assays, pFRL2 plasmid can be used alone to reduce the problems of copy-number variation and leaky transcription. Downstream of the CMV promoter is a chimeric intron. Transfection studies have demonstrated that the presence of an intron flanking a CDNA insert frequently increases the level of gene expression. The internal control Renilla luciferase is a $36-\mathrm{kDa}$ monomeric protein that does not require post-translational modification for its activity. The DNA fragment encompassing six copies of tandemly repeated sequences of HRE $(6 \times \mathrm{HRE})$ was excised from p6 $\times$ HRECAT3-CMVmini by Kpnl and Sacll digestion. This restricted fragment was then subcloned into Kpnl- and Sacll-restricted pFRL2-9 $\times$ ORE-CMVmini. The DNA fragment of $9 \times$ ORE that had been excised from pFRL2-9 $\times$ ORE-CMVmini by Kpnl digestion was inserted into the Kpnl-restricted pFRL2-6 $\times$ HRE-CMVmini to generate pFRL2- $6 \times$ HRE- $9 \times$ ORE-CMVmini. Cells $\left(1 \times 10^{5}\right)$ were transfected with $0.8 \mu \mathrm{g}$ of pFRL2-9 $\times$ ORE-CMVmini, pFRL2-6 $\times$ HRE-CMVmini or pFRL2$6 \times$ HRE- $9 \times$ ORE-CMVmini using Lipofectamine 2000 (Invitrogen, Carlsbad, CA, USA). Twenty-four hours after transfection, the cells were placed in a hypoxia chamber or cultured for $48 \mathrm{~h}$ at $37^{\circ} \mathrm{C}$. The cell lysates were then collected, and their firefly and Renilla luciferase activities were measured using a dual-luciferase reporter assay (Promega, Madison, WI, USA). The firefly luciferase activity was normalized to Renilla luciferase activity, and the relative luciferase units (RLU) were expressed as a fold activation relative to the basal level under normoxia.

\section{RNA interference of HIF-2a}

For HIF-2a knockdown experiments, pLKO.1-puro-based lentiviral vectors including stem-loop cassettes encoding shRNA targeting human HIF-2a gene (TRCN0000003804) and murine HIF-2a gene (TRCN0000082307), as well as GFP gene (TRCN0000072184), were obtained from the National RNAi Core Facility located at the Institute of Molecular Biology/Genomic Research Center, Academia Sinica, Taipei, Taiwan.

\section{Construction of recombinant adenoviruses}

The AdEasy system was used to generate AdLCY, an E1B-55-kDa-deleted adenovirus under the control of the CMVmini promoter ligated with $6 \times \mathrm{HRE}$ and $9 \times \mathrm{ORE}^{55}$ To insert a multiple cloning site on the backbone of an E1B-55-kDa adenovirus, we have constructed pAd5YS plasmid previously. ${ }^{10}$ The DNA fragment encompassing the $6 \times \mathrm{HRE}-9 \times$ ORECMVmini promoter was excised from pFRL2- $6 \times$ HRE- $9 \times$ ORE-CMVmini by Notl and Bglll digestion, and cloned into the Notl/BamHI sites of pAd5YS, resulting in pAd5YS- $6 \times$ HRE- $9 \times$ ORE-CMVmini. Subsequently, the $6 \times$ HRE- $9 \times$ ORE-CMVmini fragment was excised by $B s r G l$ and Mfel digestion and cloned into pShuttle to generate pShuttle- $6 \times$ HRE- $9 \times$ ORE-CMVmini. AdLCY was generated as previously described. ${ }^{10}$ Ad90C, which is an E1B-55-kDa-deleted adenovirus driven by the $9 \times$ ORE-CMVmini promoter, and AdLacZ, a replication-defective adenoviral vector encoding $\beta$-galactosidase, have been previously described. ${ }^{10}$ AdGFP, a replicationdefective adenoviral vector encoding GFP under the control of the CMV promoter, has been previously described. ${ }^{56}$ All recombinant adenoviruses were propagated, purified using $\mathrm{CsCl}$ density gradient centrifugation and quantified by the plaque assay.
Analysis of CPE and cell viability

For monitoring CPE, bladder cancer cells (TCC-SUP and MBT-2) and normal epithelial cells (NMUMG and SV-HUC-1) were infected with either AdLCY or Ad90C at different MOls or left uninfected under normoxic or hypoxic conditions for $48 \mathrm{~h}$. Cells were then cultured in normoxic conditions for 5 days. The CPE was visualized by fixing and staining the remaining monolayer with $10 \%$ formalin $/ 0.05 \%$ crystal violet. Cell survival was also assessed with a colorimetric WST-1 assay (Dojindo Laboratories, Tokyo, Japan).

\section{Quantitative real-time RT-PCR analysis}

Trizol (Invitrogen) was used to isolate total RNA from cells according to the manufacturer's protocols. Total RNA $(2 \mu \mathrm{g})$ was reverse-transcribed into cDNA using a Verso cDNA synthesis kit (Thermo Fisher Scientific, Barrington, IL, USA). Quantitative real-time PCR was performed using a SmartCycler System (Cephid, Sunnyvale, CA, USA) according to the manufacturer's instructions. Each reaction contained $50 \mathrm{ng}$ CDNA, SYBR Premix Ex Taq (Takara Bio, Shiga, Japan), and $5 \mu \mathrm{mol}$ of each forward and reverse primer. Two oligonucleotide primer pairs specific to Oct4 (forward, 5'-CGAAAGAGAAAGCGAACCAGTATC-3'; reverse, 5'-TTACAGAACCACACTC GGACCAC-3') and GAPDH (forward, 5'-GCCATCACTGCCACCCAG-3'; reverse, 5'- TCTTACTCCTTGGAGGCCATGT-3') were used. Normalization was performed using human glyceraldehyde-3-phosphate dehydrogenase GAPDH as an internal control, and relative gene expression was calculated using the comparative $2^{\left(-\Delta \Delta C^{\prime}\right)}$ method. ${ }^{57}$

\section{Immunoblot analysis}

Total cell lysates were collected and subjected to immunoblot analysis using rabbit antibodies against HIF-1a (Novus Biologicals, Littleton, CO, USA) and HIF-2a (Novus Biologicals), and mouse monoclonal antibody against Oct4 (C-10; Santa Cruz Biotechnology, Santa Cruz, CA, USA). Horseradish peroxidase-conjugated goat anti-rabbit $\lg G$ and goat antimouse IgG (Jackson ImmunoResearch, West Grove, PA, USA) were used as the secondary antibodies, where appropriate. The blots were reprobed with $\beta$-actin (Sigma-Aldrich, St Louis, MO, USA) which served as the loading control.

\section{Animal studies}

TCC-SUP cells $\left(5 \times 10^{6}\right)$ were inoculated subcutaneously into the right flank of NOD/SCID mice on day 0 . Groups of 5-6 mice were intratumorally treated with $5 \times 10^{8}$ plaque forming units (PFU) of AdLCY or Ad9OC, or with saline on days 21,23 and 25 . All the mice were monitored for tumor growth and survival. A tissue caliper was used to measure the tumors twice a week in two perpendicular axes, and the tumor volume was calculated as (length of tumor) $\times$ (width of tumor) ${ }^{2} \times 0.45$. The time of animal death was recorded. All moribund mice, which were killed, were also recorded as dead.

\section{Immunohistochemistry}

To detect tumor targeting of AdLCY and Ad9OC, TCC-SUP tumor-bearing mice were treated with AdLCY, Ad9OC or AdLacZ and killed on day 31 . Serial formalin-fixed paraffin sections of tumor tissues were stained with rabbit anti-adenovirus type 5 antibody (Abcam, Cambridge, UK), rabbit anti-mouse HIF-1- $a$ antibody (Abcam), mouse anti-CD44 monoclonal antibody (8E2; Cell Signaling, Danvers, MA, USA) and mouse anti-human CD133/1 monoclonal antibody (AC133; Miltenyi Biotec, Bergisch Gladbach, Germany). After they had been sequentially incubated with appropriate secondary antibodies (Jackson ImmunoResearch) for $2 \mathrm{~h}$ at room temperature with aminoethylcarbazole as the substrate chromogen (Invitrogen Zymed Laboratories, Camarillo, CA, USA), the slides were counterstained with hematoxylin.

\section{Flow cytometry}

Bladder cancer cells (TCC-SUP and MBT-2) and normal epithelial cells (SVHUC- 1 and NMuMG) $\left(1 \times 10^{6}\right.$ per analysis) were incubated on ice with antiCAR (RmcB, American Type Culture Collection, Manassas, VA, USA) monoclonal antibody for $1 \mathrm{~h}$, followed by incubation for $30 \mathrm{~min}$ on ice with FITC-conjugated goat anti-mouse antibody. Isotype immunoglobulin $\mathrm{G}$ was used as a matched control. TCC-SUP cells were infected with AdLCY, Ad9OC or AdLacZ at an MOI of 1 for 5 days. Subsequently, the cells $\left(1 \times 10^{6}\right.$ per analysis) were stained either with the phycoerythrin (PE)-conjugatedanti-CD44 antibody (IM7; eBioscience, San Diego, CA, USA) for $1 \mathrm{~h}$ at room 
temperature or with the mouse anti-human $\mathrm{CD} 133 / 1$ monoclonal antibody (AC133; Miltenyi Biotec) for $2 \mathrm{~h}$ at $4{ }^{\circ} \mathrm{C}$ followed by incubation with the fluorescein isothiocyanate-conjugated goat anti-mouse antibody (Kirkegaard \& Perry Laboratories, Baltimore, MD, USA). The cells were washed twice with the staining buffer and suspended in DMEM-based buffer for flow cytometric analysis. These samples were then analyzed with a FACSCalibur flow cytometry (Becton Dickinson, San Jose, CA, USA).

\section{Colony formation assay}

TCC-SUP cells infected with various adenoviruses at an MOI of 1 were cultured under hypoxic or normoxic conditions for $48 \mathrm{~h}$. Subsequently, cells were thoroughly dissociated with $0.1 \%$ trypsin to prepare single-cell suspension. Each well of 24-well plates was covered with a basal layer of $300 \mu \mathrm{l}$ of $0.5 \%$ agarose containing $50 \%$ complete medium (DMEM with $10 \%$ cosmic calf serum (Hyclone, Logan, UT, USA)). After the medium was solidified, $300 \mu \mathrm{l}$ of $0.35 \%$ agarose containing 2000 cells and $50 \%$ complete medium in triplicate was added to each well. These wells were then covered with $200 \mu \mathrm{l}$ of complete medium and the plates were incubated at $37^{\circ} \mathrm{C}$ for 29 days. Numbers of colonies were then counted using a cytometer (Celigo Cytometer; Cyntellect, San Diego, CA, USA) according to the manufacturer's instructions.

\section{Immunofluorescence double staining}

Tumor sections were fixed in 10\% formalin and stained with an anti-human CD133/1 (AC133; Miltenyi Biotec) monoclonal antibody and subsequently incubated with a fluorescein-conjugated secondary antibody lgG. After being washed trice with PBS, they were stained with an anti-adenovirus type 5 hexon antibody (Abcam) and subsequently incubated with a fluorescein-conjugated secondary lgG antibody. The nucleus was counterstained with 4',6-diamidino-2-phenylindole (DAPI).

\section{Statistical analysis}

All values are means \pm s.e.m. of the mean. Statistical significance between groups was assessed using Student's $t$-test. Tumor volumes were compared using two-way ANOVA. The survival analysis was performed using the Kaplan-Meier survival curve and the log-rank test. Any $P$ value of $<0.05$ is regarded statistically significant.

\section{CONFLICT OF INTEREST}

The authors declare no conflict of interest.

\section{ACKNOWLEDGEMENTS}

We thank Bert Vogelstein (John Hopkins School of Medicine) for generously providing plasmids for AdEasy System and Richard A. Hodin (Harvard Medical School) for generously providing pFRL2 plasmid. This work was supported by grants from the National Science Council (NSC 97-3112-B-006-005-001), Taiwan.

\section{REFERENCES}

1 Rankin EB, Giaccia AJ. The role of hypoxia-inducible factors in tumorigenesis Cell Death Differ 2008; 15: 678-685.

2 Ke Q, Costa M. Hypoxia-inducible factor-1 (HIF-1). Mol Pharmacol 2006; 70: 1469-1480.

3 Wang $V$, Davis DA, Haque $M$, Huang LE, Yarchoan R. Differential gene up-regulation by hypoxia-inducible factor- $1 a$ and hypoxia-inducible factor- $2 a$ in HEK293T cells. Cancer Res 2005; 65: 3299-3306.

4 Petrella BL, Lohi J, Brinckerhoff CE. Identification of membrane type-1 matrix metalloproteinase as a target of hypoxia-inducible factor-2a in von Hippel-Lindau renal cell carcinoma. Oncogene 2005; 24: 1043-1052.

5 Covello KL, Kehler J, Yu H, Gordan JD, Arsham AM, Hu CJ et al. HIF-2a regulates Oct-4: effects of hypoxia on stem cell function, embryonic development, and tumor growth. Genes Dev 2006; 20: 557-570.

6 Keith B, Simon MC. Hypoxia-inducible factors, stem cells, and cancer. Cell 2007; 129: $465-472$.

7 Heise C, Sampson-Johannes A, Williams A, McCormick F, Von Hoff DD, Kirn DH. ONYX-015, an E1B gene-attenuated adenovirus, causes tumor specific cytolysis and antitumoral efficacy that can be augmented by standard chemotherapeutic agents. Nat Med 1997; 3: 639-645.

8 Glasgow JN, Bauerschmitz GJ, Curiel DT, Hemminki A. Transductional and transcriptional targeting of adenovirus for clinical applications. Curr Gene Ther 2004; 4: 1-14.
9 Shieh GS, Shiau AL, Yo YT, Lin PR, Chang CC, Tzai TS et al. Low-dose etoposide enhances telomerase-dependent adenovirus-mediated cytosine deaminase gene therapy through augmentation of adenoviral infection and transgene expression in a syngeneic bladder tumor model. Cancer Res 2006; 66: 9957-9966.

$10 \mathrm{Wu} C \mathrm{C}$, Shieh GS, Chang CC, Yo YT, Su CH, Chang MY et al. Tumor-selective replication of an oncolytic adenovirus carrying oct-3/4 response elements in murine metastatic bladder cancer models. Clin Cancer Res 2008; 14: 1228-1238.

11 Chang CC, Shieh GS, Wu P, Lin CC, Shiau AL, Wu CL. Oct-3/4 expression reflects tumor progression and regulates motility of bladder cancer cells. Cancer Res 2008; 68: 6281-6291.

12 Hsieh JL, Lee $\mathrm{CH}$, Teo ML, Lin YJ, Huang YS, Wu CL et al. Transthyretin-driven oncolytic adenovirus suppresses tumor growth in orthotopic and ascites models of hepatocellular carcinoma. Cancer Sci 2009; 100: 537-545.

13 Chiocca EA. Oncolytic viruses. Nat Rev Cancer 2002; 2: 938-950.

14 Burke J. Virus therapy for bladder cancer. Cytokine Growth Factor Rev 2010; 21: 99-102.

15 Wang H, Cai Z, Yang F, Luo J, Satoh M, Arai Y et al. Enhanced antitumor efficacy of integrin-targeted oncolytic adenovirus AxdAdB3-F/RGD on bladder cancer. Urology 2014; 83: 508 e13-9.

16 Pol J, Bloy N, Obrist F, Eggermont A, Galon J, Cremer I et al. Trial Watch: oncolytic viruses for cancer therapy. Oncoimmunology 2014; 3: e28694.

17 Breitbach CJ, Arulanandam R, De Silva N, Thorne SH, Patt R, Daneshmand M et al. Oncolytic vaccinia virus disrupts tumor-associated vasculature in humans. Cancer Res 2013; 73: 1265-1275.

18 Heo J, Reid T, Ruo L, Breitbach CJ, Rose S, Bloomston M et al. Randomized dose-finding clinical trial of oncolytic immunotherapeutic vaccinia JX-594 in liver cancer. Nat Med 2013; 19: 329-336.

19 Kaufman HL, Ruby CE, Hughes T, Slingluff Jr CL . Current status of granulocytemacrophage colony-stimulating factor in the immunotherapy of melanoma. J Immunotherapy Cancer 2014; 2: 11

20 Monk M, Holding C. Human embryonic genes re-expressed in cancer cells. Oncogene 2001; 20: 8085-8091.

21 Atlasi Y, Mowla SJ, Ziaee SA, Bahrami AR. OCT-4, an embryonic stem cell marker, is highly expressed in bladder cancer. Int J Cancer 2007; 120: 1598-1602.

22 Yamamoto $M$, Curiel DT. Current issues and future directions of oncolytic adenoviruses. Mol Ther 2010; 18: 243-250.

23 Shen $\mathrm{BH}$, Hermiston TW. Effect of hypoxia on Ad5 infection, transgene expression and replication. Gene Ther 2005; 12: 902-910.

24 Pipiya T, Sauthoff H, Huang YQ, Chang B, Cheng J, Heitner S et al. Hypoxia reduces adenoviral replication in cancer cells by downregulation of viral protein expression. Gene Ther 2005; 12: 911-917.

25 Post DE, Van Meir EG. A novel hypoxia-inducible factor (HIF) activated oncolytic adenovirus for cancer therapy. Oncogene 2003; 22: 2065-2072.

26 Cho WK, Seong YR, Lee YH, Kim MJ, Hwang KS, Yoo J et al. Oncolytic effects of adenovirus mutant capable of replicating in hypoxic and normoxic regions of solid tumor. Mol Ther 2004; 10: 938-949.

27 Post DE, Devi NS, Li Z, Brat DJ, Kaur B, Nicholson A et al. Cancer therapy with a replicating oncolytic adenovirus targeting the hypoxic microenvironment of tumors. Clin Cancer Res 2004; 10: 8603-8612.

28 Siegel R, Naishadham D, Jemal A. Cancer statistics, 2013. CA Cancer J Clin 2013; 63 : $11-30$.

29 Thanan R, Murata M, Ma N, Hammam O, Wishahi M, El Leithy T et al. Nuclear localization of COX-2 in relation to the expression of stemness markers in urinary bladder cancer. Mediators Inflamm 2012; 2012: 165879.

30 Ruan J, Wei B, Xu Z, Yang S, Zhou Y, Yu M et al. Predictive value of Sox2 expression in transurethral resection specimens in patients with $\mathrm{T} 1$ bladder cancer Med Oncol 2013; 30: 445 .

31 Schoenhals M, Kassambara A, De Vos J, Hose D, Moreaux J, Klein B. Embryonic stem cell markers expression in cancers. Biochem Biophys Res Commun 2009; 383: 157-162.

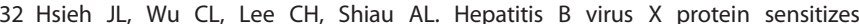
hepatocellular carcinoma cells to cytolysis induced by E1B-deleted adenovirus through the disruption of p53 function. Clin Cancer Res 2003; 9: 338-345.

33 Bergelson JM, Cunningham JA, Droguett G, Kurt-Jones EA, Krithivas A, Hong JS et al. Isolation of a common receptor for Coxsackie B viruses and adenoviruses 2 and 5. Science 1997: 275: 1320-1323.

34 Tomko RP, Xu R, Philipson L. HCAR and MCAR: the human and mouse cellular receptors for subgroup $\mathrm{C}$ adenoviruses and group B coxsackieviruses. Proc Natl Acad Sci USA 1997; 94: 3352-3356.

35 Roelvink PW, Lizonova A, Lee JG, Li Y, Bergelson JM, Finberg RW et al The coxsackievirus-adenovirus receptor protein can function as a cellular attachment protein for adenovirus serotypes from subgroups $A, C, D, E$, and $F$. J Virol 1998; 72: 7909-7915.

36 Brown JM, Wilson WR. Exploiting tumour hypoxia in cancer treatment. Nat Rev Cancer 2004; 4: 437-447. 
37 Liao D, Corle C, Seagroves TN, Johnson RS. Hypoxia-inducible factor-1a is a key regulator of metastasis in a transgenic model of cancer initiation and progression. Cancer Res 2007; 67: 563-572.

38 Li Z, Bao S, Wu Q, Wang H, Eyler C, Sathornsumetee S et al. Hypoxia-inducible factors regulate tumorigenic capacity of glioma stem cells. Cancer Cell 2009; 15 501-513.

39 Shiau AL, Shen YT, Hsieh JL, Wu CL, Lee CH. Scutellaria barbata inhibits angiogenesis through downregulation of HIF-1 a in lung tumor. Environ Toxicol 2014; 29: 363-370.

40 Lee $\mathrm{CH}, \mathrm{Wu} \mathrm{CL}$, Shiau AL. Hypoxia-induced cytosine deaminase gene expression for cancer therapy. Hum Gene Ther 2007; 18: 27-38.

41 Koh MY, Lemos Jr R, Liu X, Powis G. The hypoxia-associated factor switches cells from HIF-1a- to HIF-2a-dependent signaling promoting stem cell characteristics, aggressive tumor growth and invasion. Cancer Res 2011; 71: 4015-4027.

42 Ma W, Ma J, Xu J, Qiao C, Branscum A, Cardenas A et al. Lin28 regulates BMP4 and functions with Oct4 to affect ovarian tumor microenvironment. Cell Cycle 2013; 12: 88-97.

43 Li X, Lewis MT, Huang J, Gutierrez C, Osborne CK, Wu MF et al. Intrinsic resistance of tumorigenic breast cancer cells to chemotherapy. J Natl Cancer Inst 2008; 100: 672-679.

44 Bao S, Wu Q, McLendon RE, Hao Y, Shi Q, Hjelmeland AB et al. Glioma stem cells promote radioresistance by preferential activation of the DNA damage response. Nature 2006; 444: 756-760.

45 Bentivegna A, Conconi D, Panzeri E, Sala E, Bovo G, Viganò $P$ et al. Biological heterogeneity of putative bladder cancer stem-like cell populations from human bladder transitional cell carcinoma samples. Cancer Sci 2010; 101: 416-424.

46 Chan KS, Espinosa I, Chao M, Wong D, Ailles L, Diehn M et al. Identification, molecular characterization, clinical prognosis, and therapeutic targeting of human bladder tumor-initiating cells. Proc Natl Acad Sci USA 2009; 106: 14016-14021.
47 Mimeault M, Batra SK. Novel therapies against aggressive and recurrent epithelial cancers by molecular targeting tumor- and metastasis-initiating cells and their progenies. Anticancer Agents Med Chem 2010; 10: 137-151.

48 Semenza GL. Targeting HIF-1 for cancer therapy. Nat Rev Cancer 2003; 3: 721-732.

49 Yan X, Ma L, Yi D, Yoon JG, Diercks A, Foltz G et al. A CD133-related gene expression signature identifies an aggressive glioblastoma subtype with excessive mutations. Proc Natl Acad Sci USA 2011; 108: 1591-1596.

50 Ohnishi S, Maehara O, Nakagawa K, Kameya A, Otaki K, Fujita H et al. Hypoxia-inducible factors activate CD133 promoter through ETS family transcription factors. PLoS One 2013; 8: e66255.

51 Brown JM, Giaccia AJ. The unique physiology of solid tumors: opportunities (and problems) for cancer therapy. Cancer Res 1998; 58: 1408-1416.

52 Okunieff PG, Koutcher JA, Gerweck L, McFarland E, Hitzig B, Urano M et al. Tumor size dependent changes in a murine fibrosarcoma: use of in vivo ${ }^{31}$ P NMR for non-invasive evaluation of tumor metabolic status. Int J Radiat Oncol Biol Phys 1986; 12: 793-799.

53 Gupta PB, Chaffer CL, Weinberg RA. Cancer stem cells: mirage or reality? Nat Med 2009; 15: 1010-1012.

54 Malo MS, Abedrapo M, Chen A, Mozumder M, Pushpakaran P, Alkhoury F et al. Improved eukaryotic promoter-detection vector carrying two luciferase reporter genes. Biotechniques 2003; 35: 1150-1152; 1154.

55 He TC, Zhou S, da Costa LT, Yu J, Kinzler KW, Vogelstein B. A simplified system for generating recombinant adenoviruses. Proc Natl Acad Sci USA 1998; 95: 2509-2514.

56 Hsieh JL, Shen PC, Shiau AL, Jou IM, Lee CH, Teo ML. Adenovirus-mediated Kallistatin gene transfer ameliorates disease progression in a rat model of osteoarthritis induced by anterior cruciate ligament transection. Human Gene Therapy 2009; 20: 147-158.

57 Schmittgen TD, K.J. Livak KJ. Analyzing real-time PCR data by the comparative C(T) method. Nat Protoc 2008; 3: 1101-1108. 